\title{
Par

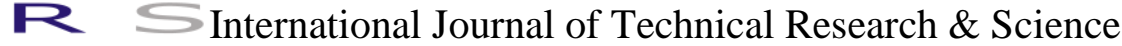 \\ A COMPARATIVE STUDY OF WORK STRESS, MENTAL WELLBEING AND FUNCTIONAL IMPAIRMENT AMONG PHYSICIANS IN PAKISTAN
}

\author{
Muqaddas Asif ${ }^{1}$, Shahnila Tariq ${ }^{2}$, Ameer B. Khoso ${ }^{3}$ \\ E-Mail Id: muqaddasasif@ hotmail.com \\ Institute of Applied Psychology, University of the Punjab, Lahore
}

\begin{abstract}
The current study examined relationship and differences between work stress, mental wellbeing and functional impairment in medical and house officers. Methods: This cross sectional study included a total of $\mathrm{N}=100$ medical officers $(n=50)$ and house officers $(n=50)$ employed at various hospitals. Outcome measures included: Work Stress Scale, Warwick-Edinburgh Mental Wellbeing Scale, Weiss Functional Impairment Rating Scale and a self-reported demographic questionnaire. Results: Findings showed a positive relationship between work stress and functional impairment in terms of self concept and social functioning. Also there was a negative relationship between mental wellbeing and functional impairment in terms of family relations, work adjustment, life skills, self concept and social functioning. Conclusion: The findings suggests a greater emphasis to improve the work
\end{abstract} environment in order to reduce stress in hospital settings.

Keywords: Functional impairment, house officers, medical officers, mental wellbeing, work stress.

\section{INTRODUCTION}

Work stress is any detrimental reaction that individuals usually have against excessive demands and pressures at working place ${ }^{1}$. Individuals within the health care profession are widely regarded as a group vulnerable to high risk of work-related stress. Medical professionals have a demanding role and have to respond the patients and their family needs in a swift manner ${ }^{2}$. But medical knowledge and procedure frequently have some uncertainities and ambiguities that create stressful work conditions as any minor mistake can be costly, irreversible and harmful to individual's life ${ }^{3}$. Contemporary researchers suggest that work stress has increased many folds and is linked with national recession globally ${ }^{4}$. It has been suggested that whenever individuals tend to put an effort to deal with everyday jobs, tasks, or some type of force that are associated with their jobs; yet face complexity, strain, unease and worry in an attempt to manage, it is at this moment work stress tends to appear ${ }^{5}$.

Work and job stressors are linked with negative physical and mental health that poses a burden on individual and society at large 6 . There are several theories outlining the causes of work stress, one explanation describes that people have different characteristics, in terms of individual characteristics and coping styles and these specific characteristics are to predict that all individuals are not affected equally by the same stress ${ }^{7}$. Another theory describes that particular conditions of work biologically induce stress, such as fear of job loss, high work load, burden, lack of control, unclear direction, risky physical working environment, long work hours, and incompatible job potential ${ }^{8}$.

Individuals with ideal mental health and well being can apprehend their abilities, can cope well with normal stresses of life, work productively and effectively, and are able to contribute to society and country's economy ${ }^{9}$. Mental wellbeing contains the mental ability to cause wellness and contentment that improve relations with others ${ }^{10,11}$ that otherwise can leads to inability to perform normal activities ${ }^{12}$. Maximum level of stress can produce low level of accomplishment and workplace stress. Three sources of stress such as feeling choked and its consequence on life; feeling of poor management and resourced; and commercing with patients' despair all are associated to stress and psychiatric illness ${ }^{13}$.

A lack of management's regarding emotional state of physicians is considered as a noteable lack of workplace stress management strategies ${ }^{14}$. Recent evidence suggests that stress and mental health has negative relationship and also, stress in the field of humanities is found to be more so as compared to technological field ${ }^{15}$. Indiginous literature on this topic is scarce. Therefore, the primary objective was to explore the relationship and differences between work stress, mental wellbeing and functional impairment in medical and house officers. Secondary objective of the study was to assess gender differences in this population.

\section{METHODS}

The study used a cross sectional research design and convenient sampling strategy to collect the data. The sample consisted of $(\mathrm{N}=100)$ medical officers $(n=50)$ and house officers $(n=50)$ working in different hospitals in Lahore, DOI Number: https://doi.org/10.30780/IJTRS.V05.I03.004

pg. 30

WWw.ijtrs.com

www.ijtrs.org 


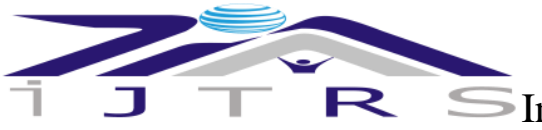

International Journal of Technical Research \& Science

Pakistan. Medical Officers (MOs) in Pakistan are qualified doctors Bachelor of Medicine and Bachelor of Surgery (MBSS), responsible for managing patients in hospital wards. They are also responsible for training of House Officers (HOs) and help them perform medical procedures. House officers are resident physician or surgeon, practicing and receiving further training in a medical or surgical specialty under the supervision of senior physician or medical officers.

\subsection{Assessment Measures}

\subsubsection{Demographic Information Questionnaire}

A self constructed demographic questionnaire was used to gather demographic information such as age, gender, education, marital status, family system and monthly income etc.

The study assessment measures included Work Stress Scale (WSS) ${ }^{16}$, The Short Warwick-Edinburgh Mental Wellbeing Scale (SWEMWBS) ${ }^{17}$ and Weiss Functional Impairment Rating Scale Self-Report (WFIRS-S) ${ }^{18}$.

\subsubsection{Work Stress Scale (WSS)}

WSS is a standardized questionnaire developed by Hargreaves (2007). The questionnaire consists of 15 items pertaining to work stress. The questionnaire has responses of the participants measured through a five point likert scale. The questionnaire has good psychometric properties.

\subsubsection{The Short Warwick-Edinburgh Mental Well-being Scale (SWEMWBS)}

SWEMWBS by Steward-Brown, et al. (2009) is a validated measure of mental wellbeing that has been used widely and seen as an effective tool with 7-item that produces a single score. It is self-reported measure (for people aged $13+$ ) to record 'statements about their thoughts and feelings. The reliability estimates for the SWEMWS is .79.

\subsubsection{Weiss Functional Impairment Rating Scale Self-Report (WFIRS-S)}

WFIRS-S was developed by Weiss (2000) to evaluate how an individual's actual ablility to function. The questions are formed to assess symptoms, the degree to which an individual's behavior or emotional problems have impacted clinical functioning. It comprises of 70 items which are rated of impairment ranges 0 to 5 . There are seven subscales named as; family, work, school, life skill, self concept, social and risk. Each subscale defines the functionality of individual on a particular domain. All items are rated on five point likert scale. The reliability of the scale is .81 .

\subsection{Procedure}

Study ethical approval was taken from institutional ethical Committee of University of the Punjab, Lahore. Permissions were obtained from the authors of the scales. Similarly, permissions were obtained for data collection from the Medical Supritendent (MS) for the participating hospitals. Before data collection, researcher explained the importance of the research and also the nature of the tools to participants. Informed consent was obtained from study participants and it was explained that their participation is completely voluntary.

\subsection{Statistical Analysis}

Data was enterd and analysed using SPSS software version 20. Reliability of the assessment scales was calculated through Cronbach Alpha reliability measure. Frequencies and percentages were calculated for demographic variables. Pearson Product Moment correlations and Independent Sample t-test's were computed to assess the relationship and differences of demographic variables, work stress, mental wellbeing and functional impairment in MOs and HOs.

\section{RESULTS}

Descriptive statistics showed that mean age of Medical officers and house officers was $M=29.26$ and $M=25.26$ respectively.A total of $46 \%$ MOs belongs to nuclear family system while $54 \%$ were living in joint family system. Whereas, $58 \%$ of HOs were from nuclear family system and $42 \%$ were from joint family system. Majority of $56 \%$ MOs were single and $44 \%$ were married. Similarly, majority of $80 \%$ HOs were single and only $20 \%$ were married (see table 1).

Table-1 Demographics Characteristics of Sample

\begin{tabular}{|c|c|c|c|c|}
\hline Characteristics & & icers & \multicolumn{2}{|c|}{ House officers } \\
\hline & \multicolumn{2}{|c|}{$(\mathrm{n}=50)$} & \multicolumn{2}{|c|}{$(\mathrm{n}=50)$} \\
\hline & $f(\%)$ & $M(S D)$ & $f(\%)$ & $M(S D)$ \\
\hline Family system & & & & \\
\hline
\end{tabular}




\begin{tabular}{|l|l|l|l|l|l|l|}
\hline Nuclear & & $23(46)$ & & & $29(58)$ & \\
\hline Joint & & $27(54)$ & & & $21(42)$ & \\
\hline Marital status & & & & & & \\
\hline Married & & $28(56)$ & & & $40(80)$ & \\
\hline Age & & $22(44)$ & & & $10(20)$ & \\
\hline
\end{tabular}

Note. $\mathrm{N}=100, \mathrm{f}=$ frequency, $\mathrm{M}=$ mean, $\mathrm{SD}=$ standard deviation

Results described in table 2 indicated that work stress, mental wellbeing and functional impairment exhibited certain correlations. The results demonstrated that mental wellbeing had a significant negative relationship with functional impairment in domains of social concept and social functioning. Moreover, work stress was positively correlated with functional impairment in domains of family relations, work adjustment, life skills, self concept and social functioning.

Table-2 Correlation of Study Variables

\begin{tabular}{|l|l|l|l|l|l|l|l|l|l|}
\hline Variables & $\mathbf{1}$ & $\mathbf{2}$ & $\mathbf{3}$ & $\mathbf{4}$ & $\mathbf{5}$ & $\mathbf{6}$ & $\mathbf{7}$ & $\mathbf{8}$ & $\mathbf{9}$ \\
\hline 1. Mental wellbeing & & -.12 & -.14 & -.08 & -.02 & $-.45^{* *}$ & $-.27^{* *}$ & -.035 & -.17 \\
\hline 2. Work stress & & - & $.43^{* *}$ & $.44^{* *}$ & $.44^{* *}$ & $.32^{* *}$ & $.22^{*}$ & .045 & $.58^{* *}$ \\
\hline 3. Family relations & & & - & $.41^{* *}$ & $.43^{* *}$ & $.41^{* *}$ & $.37^{* *}$ & .13 & $.57^{* *}$ \\
\hline 4. Work adjustment & & & & - & $.58^{* *}$ & $.49^{* *}$ & $.32^{* *}$ & $.31^{* *}$ & $.72^{* *}$ \\
\hline 5. Life skills & & & & & - & $.58^{* *}$ & $.32^{* *}$ & $.32^{* *}$ & $.74^{* *}$ \\
\hline 6. Self concept & & & & & & - & $.51^{* *}$ & $.27^{* *}$ & $.68^{* *}$ \\
\hline 7. Social functioning & & & & & & & - & .17 & $.55^{* *}$ \\
\hline 8. Risk taking & & & & & & & & - & \\
\hline $\begin{array}{l}\text { 9.Functional } \\
\text { Impairment }\end{array}$ & & & & & & & & & - \\
\hline
\end{tabular}

Note. $\mathrm{N}=100, * \mathrm{p}<.05, * * \mathrm{p}<.01$

Findings from T-tests revealed that there was a significant difference in mental wellbeing within medical and house officers. The mental wellbeing of medical officers was better in comparison to house officers. Further, there were no significant difference between work stress and functional impairment in medical and house officers.

Table-3 Comparison of Work Stress, Mental Wellbeing and Functional Impairment in Medical Officers and House Officers

\begin{tabular}{|c|c|c|c|c|c|c|c|c|c|}
\hline \multirow[t]{2}{*}{ Variable } & \multicolumn{2}{|c|}{$\begin{array}{c}\begin{array}{c}\text { Medical } \\
\text { officers }\end{array} \\
(n=50)\end{array}$} & \multicolumn{2}{|c|}{$\frac{\text { House officers }}{(n=50)}$} & \multirow[t]{2}{*}{$t$} & \multirow[t]{2}{*}{$p$} & \multicolumn{2}{|c|}{$\begin{array}{l}95 \% \text { CI of } \\
\text { difference }\end{array}$} & \multirow[t]{2}{*}{ Cohen's $d$} \\
\hline & $M$ & $S D$ & $M$ & $S D$ & & & $L L$ & $U L$ & \\
\hline Work stress & 43.26 & 8.51 & 43.24 & 7.54 & .012 & .99 & -3.17 & 3.21 & 0.00 \\
\hline Mental wellbeing & 26.36 & 4.94 & 24.36 & 4.15 & 2.18 & .031 & .18 & 3.81 & 0.43 \\
\hline Family & 17.72 & 5.13 & 16.70 & 5.59 & .95 & .34 & -1.11 & 3.15 & 0.19 \\
\hline Work & 20.38 & 6.30 & 20.58 & 6.88 & -.15 & .88 & -2.80 & 2.40 & -0.02 \\
\hline Life skills & 26.34 & 6.72 & 26.46 & 6.47 & -.09 & .92 & -2.74 & 2.50 & -0.18 \\
\hline Self concept & 9.16 & 3.40 & 9.68 & 4.04 & -.65 & .49 & -2.00 & .963 & -0.13 \\
\hline Social & 14.24 & 4.62 & 15.64 & 5.12 & -1.43 & .15 & -3.33 & .537 & -0.28 \\
\hline Risk & 27.32 & 12.4 & 29.12 & 14.93 & -.65 & .51 & -7.25 & 3.65 & -0.13 \\
\hline $\begin{array}{l}\text { Functional } \\
\text { impairment }\end{array}$ & 1.15 & 26.8 & 1.18 & 29.32 & -.53 & .59 & .14 .1 & 8.12 & -0.01 \\
\hline
\end{tabular}

Note. $\mathrm{N}=100, \mathrm{M}=$ mean, $\mathrm{SD}=$ standard deviation, $\mathrm{LL}=$ lower limit, $\mathrm{UL}=$ upper limit

Similarly, t-test results also revealed that there were no gender differences in work stress, mental wellbeing and functional impairment in medical and house officers (see table 4). 


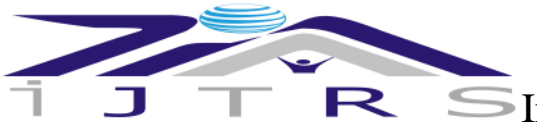

International Journal of Technical Research \& Science

Table-4 Gender Comparison in Work Stress, Mental Wellbeing and Functional Impairment of Medical Officers and House Officers

\begin{tabular}{|c|c|c|c|c|c|c|c|c|c|}
\hline \multirow[t]{2}{*}{ Variable } & \multicolumn{2}{|c|}{$\begin{array}{l}\text { Males } \\
(\mathrm{n}=50)\end{array}$} & \multicolumn{2}{|c|}{$\begin{array}{c}\text { Females } \\
(n=50)\end{array}$} & \multirow[t]{2}{*}{$t$} & \multirow[t]{2}{*}{$p$} & \multicolumn{2}{|c|}{$\begin{array}{l}95 \% \text { CI of } \\
\text { difference }\end{array}$} & \multirow[t]{2}{*}{ Cohen's d } \\
\hline & $M$ & $S D$ & $M$ & $S D$ & & & $L L$ & $U L$ & \\
\hline Work stress & 43.62 & 8.55 & 42.88 & 8.55 & .46 & .64 & -2.44 & 3.92 & 0.08 \\
\hline Mental wellbeing & 25.72 & 4.33 & 25.00 & 4.99 & .77 & .44 & -1.13 & 2.57 & 0.15 \\
\hline Family & 17.20 & 5.84 & 17.22 & 4.90 & -.01 & .98 & -2.16 & 2.12 & 0.03 \\
\hline Work & 21.78 & 7.15 & 19.18 & 5.59 & 2.02 & .06 & 0.05 & 5.14 & 0.40 \\
\hline Life skills & 25.70 & 6.97 & 27.10 & 6.13 & -1.06 & .28 & -4.00 & 1.20 & 0.21 \\
\hline Self concept & 9.34 & 3.92 & 9.50 & 3.56 & -.21 & .83 & -1.64 & 1.32 & 0.04 \\
\hline Social & 15.44 & 4.91 & 14.44 & 4.89 & 1.01 & .31 & -.94 & 2.94 & 0.20 \\
\hline Risk & 26.96 & 11.31 & 29.48 & 15.75 & -.91 & .36 & -7.96 & 2.92 & 0.66 \\
\hline Functional impairment & 1.16 & 30.74 & 1.16 & 25.21 & -.08 & .92 & -11.6 & 10.65 & 0.0 \\
\hline
\end{tabular}

Note. $\mathrm{N}=100, \mathrm{M}=$ mean, $\mathrm{SD}=$ standard deviation, $\mathrm{LL}=$ lower limit, $\mathrm{UL}=$ upper limit

\section{DISCUSSION}

The study found a positive relationship between work stress and functional impairment (self concept and social functioning) illustrating medical and house officers with higher work stress have more impairment in self concept and social functioning. Existing literature also confirmed the present findings, as Ramirez, Graham, Richards and Gregory ${ }^{19}$ highlighted that low job stress significantly protected consultants' mental health. Similarly, sources of stress was linked with burnout, psychological issues, feeling burdened, and its effect on home life; poor management and resourced as well as dealing patients' and their sufferings ${ }^{19}$.

Furthermore, mental wellbeing had a significant negative correlation with functional impairment. The results suggest that if one is functionally impaired in one domain of life it can also affect functional impairment in other domains of life. This suggests that medical and house officers with poor mental wellbeing have more impairment in family relations, work adjustment, life skills, self concept and social functioning. Thus, doctors with more functional impairment reported poorer mental wellbeing. Similar results were also found in a study by Leonard, Fanning, Attwood that showed prolonged periods of duty without sleep, can effect a doctor's well being as well as their ability to carry out simple tasks.

There was a significant difference in mental wellbeing between medical officers and house officers. Medical officers had better mental wellbeing as compared to house officers however, there were no difference in work stress and functional impairment. There might be various other reasons for such results as house officers have long periods of duty hours that can effect their mental well being ${ }^{20}$ due to poor sleep and work-life balance. Religion, culture, race, ethnicity and a persons own mindset plays an important role. Previous work suggested that junior doctors had poorer mental health than senior doctors ${ }^{21}$ and work stress has disastrous effects and its impacts our well being either positively or negatively ${ }^{22-24}$.

Moreover, findings from this study and previous literature indicated that both male and female doctors have no significant difference in work stress, mental wellbeing and functional impairment (Rout, 2000). The present study provides evidence for the relationship of work stress, mental wellbeing and functional impairment in medical and house officers. However, a few limitations should be acknowledged.

As, a cross sectional research design was employed in the study, it was not possible to draw casual inferences from current research. Future research using longitudinal or experimental research design can help to identify a pathway of these variables over time on in different conditions where causal direction can be clarified. The current research can only be implemented in the hospital settings and help us to understand how work stress and mental wellbeing affect functionality of doctors. The study suggests evaluation the most appropriate measures to improve the efficiency of work and reduce their work stress within a hospital setting.

Ethical Approval: Ethical approval was taken from institutional ethics committee. 


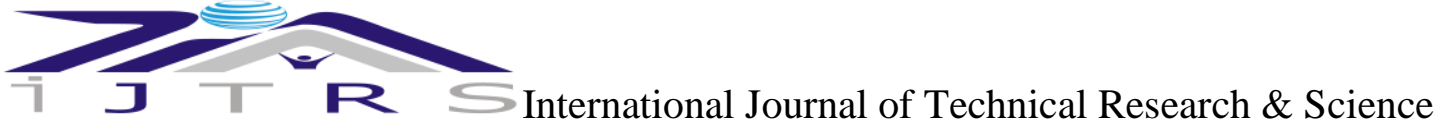

\section{REFERENCES}

[1] Health and Safety Executive. (2015). Work Related Stress, Anxiety and Depression Statistics in Great Britain 2015. Retrieved from http://www.hse.gov.uk/statistics/causdis/stress/stress.pdf).

[2] Yang, T., Guo, Y., Ma, M., Li, Y., Tian, H., \& Deng, J. (2017). Job Stress and Presenteeism among Chinese Healthcare Workers: The Mediating Effects of Affective Commitment. International Journal of Environmental Research and Public Health, 14(9). doi: 10.3390/ijerph14090978.

[3] Chou, L., Li, C., \& Hu, S. C. (2014). Job stress and burnout in hospital employees: comparisons of different medical professions in a regional hospital in Taiwan. British Medical Journal, 4, e004185. doi: 10.1136/bmjopen-2013-004185

[4] Evans-Lacko, S., Knapp, M., McCrone, P., Thornicroft, G., \& Mojtabai, R. (2013). The mental health consequences of the recession: economic hardship and employment of people with mental health problems in 27 European countries. PLoS One, 8(7), e69792. doi:10.1371/journal.pone.0069792

[5] Stranks, J. (2015). Stress at Work: Management and Prevention. Elsevier Butterworth-Heinemann.

[6] Ganster, D. C., \& Rosen, C. C. (2013) Work stress and employee health: a multidisciplinary review. J Manage, 39(5), 1085-122.

[7] Pearlin, L. I. (2009). The life course and the stress process: some conceptual comparisons. The journals of gerontology. Series B, Psychological sciences and social sciences, 65B(2), 207-15.

[8] Randall, A. K., \& Bodenmann, G. (2009). The role of work stress on close relationships and marital satisfaction. Journal of clinical psychology review, 29(2):105-15. doi: 10.1016/j.cpr.2008.10.004.

[9] WHO. (2014). Mental Health: a state of wellbeing. Retrieved from https://www.who.int/features/factfiles/mental_health/en/

[10] Slade M. (2010). Mental illness and well-being: the central importance of positive psychology and recovery approaches. BMC health services research, 10, 26. doi:10.1186/1472-6963-10-26

[11] Dillon, M. (2010). Psychological resilience and positive emotional granularity: Examining the benefits of positive emotions on coping and health, Social Sciences \& Medicine, 72(6), 1161-1190. doi: 10.1111/j.14676494.2004.00294.x

[12] Abdel-Rehman, E. M. O., Merrick, J., \& Balogun, R. A. (2012).Functional impairment: Management, types and challenges. Taylor \& Francis: London.

[13] Cruz, S. P., \& Abellan, M. V. (2015). Professional burnout, stress and job satisfaction of nursing staff at a university hospital. Rev. Latino-Am. Enfermagem, 23(3):543-52. doi: 10.1590/0104-1169.0284.2586

[14] Koinis, A., Giannou, V., Drantaki, V., Angelaina, S., Stratou, E., \& Saridi, M. (2015). The impact of healthcare workers job environment on their mental-emotional health. Coping strategies: the case of a local general hospital. Health Psychology Research, 3, 12-17.

[15] Mostafaei, A. (2012). The relationship between stress and mental health in university students.Annals of Biological Research, 3 (7), 3468-3473

[16] Hargreaves, G. (1998). Stress Management. The Essential Guide to Thinking and Working Smarter. New York: Marshall Publishing Limited.

[17] Stewart-Brown S, Tennant A, Tennant R, et al. Internal construct validity of the Warwick-Edinburgh Mental Well-being Scale (WEMWBS): A Rasch analysis using data from the Scottish Health Education Population Survey. Health Qual Life Outcomes 2009;7:1-8.

[18] Weiss, M. (2000).Functional impairment rating scale-self report.Retrieved from http://www.google.com.pk/url?sa=t\&rct=j\&q=\&esrc=s\&source=web\&cd=2\&cad=rja\&uact=8\&ved=0CCAQF jAB\&url=http\%3A\%2F\%2Fnaceonline.com\%2Fscreening_tools\%2FWeiss_Functional_Impairment_Rating_S cale_Self-Report_WFIRS-

S.pdf\&ei=G8fGU6SiJq6X0QWKq4CYAg\&usg=AFQjCNGOP3HyLjm4eF7fquIEABkjiC5sdw\&sig2=azXOt VCfcLMhdkJ5ZzsanA\&bvm=bv.71126742,d.d2k

[19] Ramirez, A.J., Graham, J., Richard, M. A. \& Gregory, W. M. (2000). Mental health of hospital consultants : the effects of stress and satisfaction at work. Lancet. 347, 324-28.

[20] Rajgopal T. (2010). Mental well-being at the workplace. Indian journal of occupational and environmental medicine, 14(3), 63-65. doi:10.4103/0019-5278.75691.

[21] Gong, Y., Han, T., Chen, W., Dib, H. H., Yang, G., Zhuang, R., ... Lu, Z. (2014). Prevalence of anxiety and depressive symptoms and related risk factors among physicians in China: a cross-sectional study. PloS one, 9(7), e103242. doi:10.1371/journal.pone.0103242.

[22] Tyssen, R., Vaglum, P., Gronvold, N. T., \&Ekeberg, O. (2001). Factors in medical school that predict postgraduate mental health problems in need of treatment: A nationwide and longitudinal study. Medical Education, 35, 110-120. 
7 T $\mathrm{R} S$ International Journal of Technical Research \& Science

[23] De Ruyter, A. \& Burgess, J. 2000. 'Job security in Australia: Broadening the analysis', Australian Journal of Social Issues, 35: 215.

[24] Torkelson, E., \& Muhonen, T. (2003a). Stress and Health among Women and Men in a Swedish Telecom Company. European Journal of Work and Organizational Psychology, 12(2), 171-186. 